\title{
Application of Blockchain Technology in Commercial Banks
}

\author{
Qingquan HE \\ Department of Finance, Insurance Professional College, changsha, china
}

\begin{abstract}
Blockchain technology is widely used in finance, digital asset trading and other fields because of its characteristics of decentralization, unforgeability and sharing. Blockchain has become one of the hot topics in fintech research, which affects the development of traditional financial formats. It is considered as the cornerstone of digital economy. This paper systematically analyzes the characteristics of blockchain technology, the impact of blockchain technology on the operation and management of traditional commercial banks, and prospects the application of blockchain technology in commercial banks.
\end{abstract}

\section{INTRODUCTION}

With electronic payment dominating the mainstream, the once familiar paper money transaction has been declining. Application scenarios of central bank digital currency have tested at the end of April 2020, which will be "practiced" for the future official issuance. For example, organs and enterprises at all levels in Xiangcheng District of Suzhou will use digital currency as a pilot in wage payment, and the future Winter Olympics scenario is also expected to be used as the application scenario of the test. Digital currency based on blockchain technology disturbs the financial industry and promotes the development of financial industry.

Since its appearance in 2008, blockchain technology has become one of the hot topics in fintech research, and has penetrated into all fields of traditional financial market, affecting the operation mode of financial industry operation system and even the whole social and commercial system ${ }^{[1]}$. It will change the operation rules and financial formats of the traditional financial industry, and also change the basic transaction process and financial industry starting from the technical level The basic principles of financial transactions and the corresponding regulatory system ${ }^{[2]}$.

Blockchain technology is a new type of globally shared, traceable and digital distributed ledger, which has the characteristics of decentralization, high credibility, openness, sharing, and unforgeability. Blockchain technology is widely used in finance, intelligent manufacturing, supply chain management, digital asset trading and other fields. It is widely used in many fields, such as digital financial transaction and digital manufacturing. It is regarded as the cornerstone of digital economy ${ }^{[3]}$. Digital currency with blockchain technology as the core gives full play to the characteristics of blockchain technology. It is applied to various business processes of commercial banks. By changing the basic transaction process and transaction criteria of commercial banks, it improves transaction efficiency and prevents fraud and operational risks ${ }^{[4-6]}$.

\section{ChARACTERISTICS OF BLOCKCHAIN TECHNICAL}

\subsection{Distributed accounting}

In terms of accounting, blockchain does not need to rely on a central organization to be responsible for accounting. Each nodes competes for the accounting right fairly through the calculation power or the rights and interests.In fact, this competition mechanism is one of the biggest differences between blockchain and traditional database. Through "whole network witness", all transaction information will be "truthfully recorded", and this account book will be unique. In the traditional double entry accounting, each institution only keeps its own accounts, but it often costs a lot of middle and back office costs for reconciliation and liquidation. This inefficient way will be completely changed by the blockchain. 


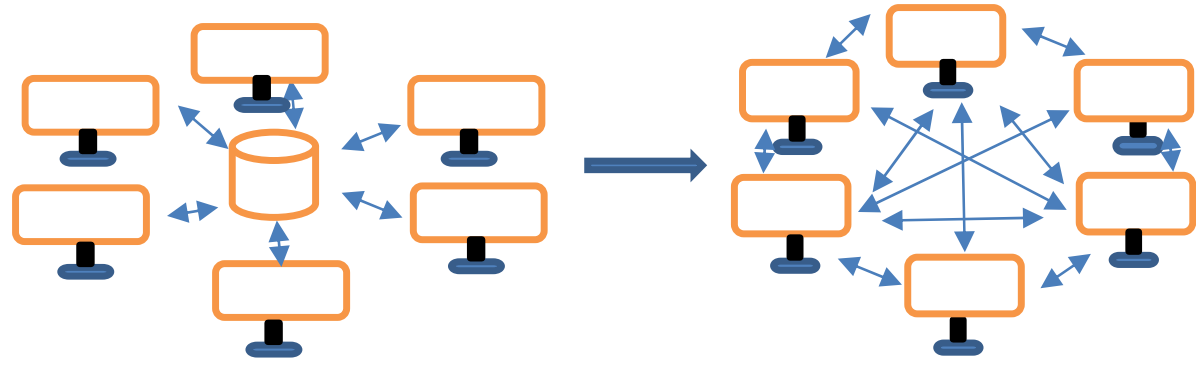

Fig 1: The difference of Centralization data model and "Distributed" data model

\subsection{Unmodifiable}

Unmodifiable means that the data records in the blockchain can't be modified. If the data record of the kth block in the blockchain is modified, then according to the characteristics of the data structure of the blockchain, the header hash of the current block will change. Because the hash function has collision resistance. The changed header of the hash will not match the parent hash of the $\mathrm{k}+1$ block. And the tamper needs to continue to modify the parent hash of the $\mathrm{k}+1$ block and continue to modify each block afterwards. This requires the tamper to simultaneously invade all the nodes participating in the record and tamper with the data at the same time. Only after recalculating all subsequent blocks of the changed block and catching up with the progress of the legal blockchain in the network, the long Blockchain forks are submitted to other nodes in the network before they can be recognized. In many cases, the difficulty of generating a new block is not small, and the computational difficulty of continuously generating multiple blocks to form a new fork is even more amazing. In the context of the huge computing power of the entire network, a malicious node needs to have at least $51 \%$ of the computing power of the entire network to achieve this. Since the blockchain is a distributed system, most nodes are independent of each other. "51\% attack" is hard to happen in reality.

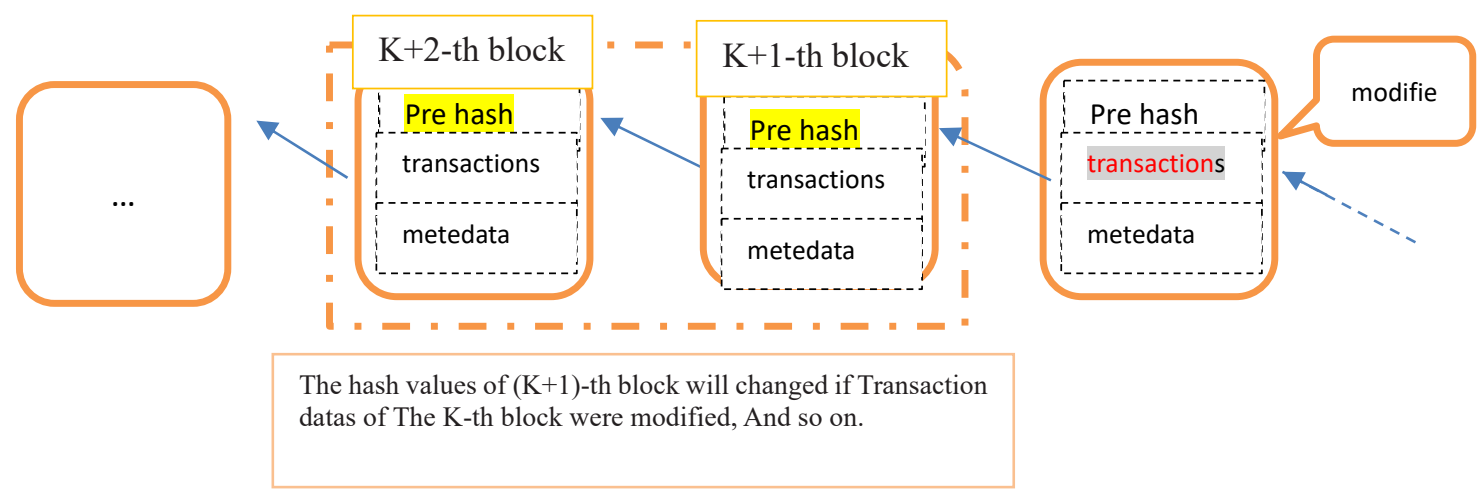

Fig2: the Change diagram of hash values when transaction datas modified.

\section{THE IMPACT OF BLOCKCHAIN TECHNOLOGY ON COMMERCIAL BANKS}

Blockchain technology uses data encryption, consensus mechanisms, time stamps, smart contracts and other technical means to realize peer-to-peer transactions, coordination and collaboration in distributed systems. The new digital distributed accounting created by blockchain technology has the characteristics of distributed, Unmodifiable, traceability, openness, algorithmic trust, etc. It is widely used in finance, intelligent manufacturing, supply chain management, digital asset transactions, etc. The field is considered to be he cornerstone of the digital economy, which can solve the problems of data security, collaborative efficiency and risk control in a centralized structure [3]. Blockchain technology impact commercial banks in the fields of business models, risk prevention, and business management.

\subsection{The impact on the competitive model of commercial banks}

Before the wide application of fintech, banks were in an absolutely strong position. There were only two possibilities in the process of customer business processing. One is to meet the banking business processing standards and become a bank customer, but they must passively accept various bank requirements and corresponding deposit and loan interest rates. ; Second, 
they did not meet the requirements of the bank, and were refused service. The large number of bank outlets means that there are many banking services. The number of outlets is the main source of bank profits. However, with the wide application of financial technology, especially the use of Internet technology and blockchain technology, some businesses that must be completed at the counter, such as Transfers are now transferred to mobile banking, online banking and other mobile services. The competition of traditional banks has transformed from the competition for the number of outlets to the competition of financial technology applications.

\subsection{The impact on risk prevention of commercial banks}

Traditional banks tend to use mortgage guarantees as the main means of risk prevention in the process of borrowing and lending to customers because they have little knowledge of customer information. With the promotion and application of financial technology, banks use Internet technology to investigate customer past transaction information. While blockchain technology The noneditable modification of the system can ensure the authenticity and reliability of information resources such as customer information and transaction records, thereby facilitating the .transformation of bank risk control from single-point risk control to comprehensive risk control and real-time information analysis.

\subsection{The impact on the management of commercial banks}

With the widespread promotion and application of Taobao and other e-commerce companies around the world, crossborder transactions have become an important part of domestic e-commerce. The high settlement cost, the low proportion of business and the uncertainty of the counterparty make it difficult to build a direct partnership. Generally, when the business volume is not large, the settlement of cross-border institutions is handled by the correspondent bank, but the existence of the correspondent bank, the communication of the agreement and the repeated confirmation of transaction information during the settlement process make the settlement cycle take 3-5 days on average, which is inefficient. Applying blockchain technology to the cross-border payment field of commercial banks is equivalent to creating a peer-topeer network between multinational banks. The transaction needs of the remitting banks can be matched directly, which greatly reduces the liquidity in the traditional cross-border clearing system Loss, capital operation and exchange costs.

\section{APPLICATION PROSPECTS OF BLOCKCHAIN TECHNOLOGY IN COMMERCIAL BANKS}

With economic and social development, modern technologies such as big data, artificial intelligence, and blockchain have become more and more widely used in various industries. The emergence of blockchain-based digital currencies is a sign of the application of blockchain technology in the financial industry. In line with the development trend of the future financial industry. In order to accelerate the further promotion and application of blockchain technology, the banking industry, on the one hand, should study the characteristics of blockchain technology and the integration with banking business.On the other hand, the banking industry also accelerate the application of blockchain technology in banking Research on application scenarios. So the application of blockchain technology Promote the development of the banking industry.

\subsection{Actively research blockchain technology and its application scenarios}

As the main financial institution, commercial banks should follow the trend of economic and technological development and actively adapt it. Electronic money based on blockchain technology has the characteristics of distributed ledger and decentralization,which will affect the function of commercial banks' money payment intermediary and credit intermediary.It also weaked the functions of commercial bank payment intermediary and credit intermediary. But the digital currency based on blockchain technology can improve the quality and speed of financial services. For example, in complex transaction projects, multiple transaction subjects are often involved, and multi-party communication and verification are required. Blockchain technology can simplify the above problems. Through coding operating rules or protocols to reduce manual intervention, smart contracts in the blockchain technology can provide more efficient and standardized financial services. Therefore, commercial banks must actively study the application of modern technology in the banking industry, maximize the role of blockchain technology and digital currency, and reduce the impact of modern technology on banks.

\subsection{Banking business application scenarios based on blockchain technology}

More and more application scenarios in banking business used blockchain technology. For example, blockchain technology is used in the field of information transmission and credit transaction processes involving multiple parties, including cross-border payment, supply chain financing, asset management, and electronics. Bills and cross-bank and cross-institution customer information sharing, reconciliation and clearing, etc.

\subsubsection{APPLICATION IN SUPPLY CHAIN FINANCING}

Information fragmentation and inability to transfer credit are the main problems in traditional supply chain financing. Using the difficult-to-tamper characteristics of the blockchain can ensure the authenticity of transactions, reduce banks' concerns about information tampering, and reduce the financing costs of SMEs. In addition, in the 
settlement of funds between enterprises, using the programmable feature of smart contracts, banks use blockchain technology to pre-set conditions in smart contracts such as core enterprise settlement and repayment periods to realize automatic transfer of repayment funds to the bank. Improve bank efficiency.

\subsubsection{APPLICATION IN TRADE FINANCE}

In the traditional business process, the trade finance business mainly adopts semi-manual operation, the transaction link is not transparent, the authenticity of the background information of the trade subject is difficult to verify, and the information transmission, identity authentication, data security and other aspects need to be improved. Banks can use the blockchain technology to establish an inter-bank message interaction network in the form of alliance chains. And they also strengthed the exchange of information flow, cargo flow and capital flow between trading entities, which improve information transparency between participants.At last, application of the blockchina technology improved transaction efficiency; In addition, the immutable nature of blockchain technology can help banks identify the authenticity of the trade background and identify and prevent financing risks.

\section{ConCLUSION}

The development of modern financial technology has promoted the development of the financial industry. As the main technology of financial technology, the application of blockchain technology in the banking industry has not only changed the business management model, but also affected the banking business, such as payment means, intermediary business, debt and the development of asset business. The application of blockchain technology also brings serious challenges. The widespread application of financial technology including blockchain technology is the future development trend of the banking industry. Commercial banks should actively study the characteristics of modern financial technology and the impact of technological development on banking business. They should use the latest technology to develop various applications suitable for banking to improve efficiency and reduce risks.then they will seize the opportunity in the application and development of financial technology in the future.

\section{ACKNOWLEDGMENT}

This paper is the research results of the key project of insurance Vocational College (Project No. A2018001).

\section{AUTHOR:}

Qingquan HE (1975 -), Ph.D., associate professor, Main research fields: financial technology, behavioral finance, etc

\section{REFERENCE}

1. JianXie Guo. Application of blockchain technology in traditional business innovation of commercial banks [J]. Journal of Market Modernization. 2019, 12:114115.

2. Miaoyan Li, Lihui Hi, Jing Li.Impact,shaping and risk analysis of blockchain technology on financial system[J]. Journal of Macroecono-mic Research. $2017.6: 50-55$.

3. Xueming $\mathrm{Si}$, Wenguang Chen. Introduction of blockchain and digital currency Technology [J]. Journal of Software,2019,30(6):1575-1576.

4. Broadbent, Ben "Central Banks and Digital Currencies" available at http : //www.bankofengland.co.uk/publications/Documents/speeches/ 2016/speech886.pdf, 2016.

5. Ting ZHANG. Application and Prospect of blockchain technology in China's commercial banks [J]. Journal of New Finance.2019.7:51-57

6. Qiang Wang. Blockchain is the reform opportunity of traditional banks [J]. Journal of Times Finance, 2018.30:101-102.

7. Yinggui Wang, Huiya Liang. The impact of financial technology on the value chain of commercial banks and Countermeasures [J]. Journal of New Finance, 2018 (3), 53-58. 